\title{
あるクラスのむだ時間系の平衡実現近似*
}

\author{
泉智紀**。巟島 晃** 石島辰太郎**
}

\section{Balanced Reduction for a Class of Time Delay Systems*}

\author{
Tomonori Izumi**, Akira KoJImA** and Shintaro IshiJima**
}

\begin{abstract}
A calculation method of Hankel singular values is discussed for input and unilateral time delay systems. For input time delay systems, whose channels involve different value of time delays independently, the Hankel singular values are obtained based on a matrix Lyapunov equation. By introducing auxiliary systems for the unilateral time delay system, it is shown that the singular values are characterized based on the preliminary results for input time delay systems. When Hankel singular values and vectors are derived for input and unilateral time delay systems, the calculation method of balanced reduction is constructed. We investigate balanced reduction with numerical examples.
\end{abstract}

\section{1.はじめに}

系の低次元化の一手法として, 入出力関係を良好に保 存する平衡実現近似3)が知られている。これを求めるに はハンケル特異値を計算する必要があり，その計算法が さまざまな系に対して研究されている.むだ時間を含む 系においては，1) 入力にむだ時間が存在する系8),10)-12), 2)一方向性むだ時間系5),9), においてハンケル特異值と 特異ベクトルの計算法が得られている。しかし2)の場合 は発見的に解を構成する必要があり，より一般的な系に 対する解法は得られていなかった。

本稿では，複数の入力むだ時間が独立したチャネルに 存在する系と, 風洞や圧延機のモデルとして知られてい る一方向性むだ時間系のハンケル特異值の計算法を整理 し，一方向性むだ時間系に対する計算が，入力むだ時間 系の結果に帰着できることを示す。この解法は，ハンケ ル特異值と特異ベクトルが系の入出力関係を表す量であ り，系の状態の定め方に依存しないという性質に基づい たものである。また, 入出力の間に直列にむだ時間が存

* 原稿受付 1998 年 8 月 6 日

** 東京都立科学技術大学 工学部 Tokyo Metropolitan Institute of Technology; Asahigaoka 6-6, Hino city, Tokyo 191-0065, JAPAN

Key Words: input time delay system, unilateral time delay system, controllability/observability gramian, Hankel singular value, balanced reduction.
在する系であれば, より一般的な構造をもつ系にも適用 することができる. そして, 解析的に与えられたハンケ ル特異値と特異べクトルから平衡実現近似の計算法を導 き, 数值計算により近似系を求める.

以下では, はじめにハンケル特異値の計算の基本とな る入力むだ時間系を定義し, グラミアンとハンケル特異 值の導出法を述べる。つぎに，一方向性むだ時間系に対 し, 状態の定義をかえた 2 種類の補助系を導入し, これ らの性質を明らかにする. そして, 補助系のグラミアン が入力むだ時間系に扔ける解法で与えられることを示し， これらの結果から一方向性むだ時間系のハンケル特異值 と特異ベクトルを求める. 最後に平衡実現近似を求め, 数值例を示す.

\section{2. 入力むだ時間系}

ここでは, 複数の入力むだ時間が独立したチャネルに 存在する系に注目し, ハンケル特異值と特異ベクトルの 計算法を明らかにする（Fig. 1).このような系に対して は参考文献 10)にて 2 種類のむだ時間を扱った場合が報 告されており，また，一般の場合についての計算の方針 が述べられている．以下では，任意の個数のむだ時間を 含む系（Fig. 1) に注目し，ハンケル特異值が超越方程式 の根により特徵づけられ, 特異ベクトルが常微分方程式 の解により与えられることを明らかにする。ここに導か 


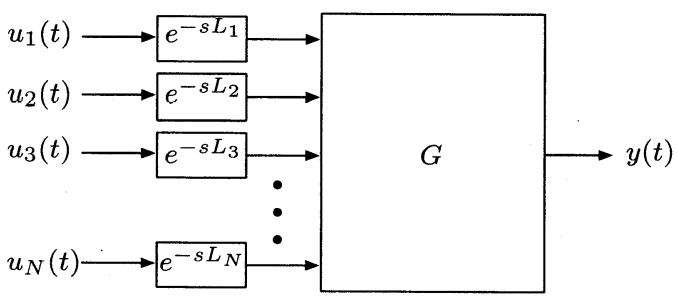

Fig. 1 Input time delay system

れる一般的な結果は, 一方向性むだ時間系のハンケル特 異值の計算に援用することができる.

\section{1 入力むだ時間系の記述}

つぎのように入力むだ時間 $L_{1}, L_{2}, \cdots, L_{N}$ を独立した チャネルに有する系

$$
\begin{aligned}
& \Sigma_{1}:\left\{\begin{array}{r}
\dot{x}(t)=A x(t)+B_{1} u_{1}\left(t-L_{1}\right) \\
+B_{2} u_{2}\left(t-L_{2}\right)+\cdots \\
\\
\cdots+B_{N} u_{N}\left(t-L_{N}\right) \\
y(t)=C x(t)
\end{array}\right. \\
& u_{i}(t) \in R^{m_{i}} \quad(i=1,2, \cdots, N) \\
& x(t) \in R^{n}, y(t) \in R^{r} \\
& B=\left[\begin{array}{lll}
B_{1} \quad B_{2} & \cdots B_{N}
\end{array}\right] \\
& L_{1} \geq L_{2} \geq \cdots \geq L_{N}>0
\end{aligned}
$$

を考える (Fig. 1). ここで, $(C, A, B)$ は可観測, 可制御, 行列 $A$ は安定であるとする.

この系の状態空間を

$$
\begin{aligned}
\mathcal{X}:= & R^{n} \times L_{2}\left(-L_{1}, 0 ; R^{m_{1}}\right) \\
& \times L_{2}\left(-L_{2}, 0 ; R^{m_{2}}\right) \times \cdots \times L_{2}\left(-L_{N}, 0 ; R^{m_{N}}\right)
\end{aligned}
$$

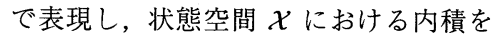

$$
\begin{aligned}
& \langle\psi, \phi\rangle:=\psi^{0 T} \phi^{0}+\sum_{i=1}^{N} \int_{-L_{i}}^{0} \psi^{i T}(\beta) \phi^{i}(\beta) \mathrm{d} \beta \\
& \phi:=\left(\phi^{0}, \phi^{1}, \cdots, \phi^{N}\right) \in \mathcal{X}, \psi:=\left(\psi^{0}, \psi^{1}, \cdots, \psi^{N}\right) \in \mathcal{X}
\end{aligned}
$$

と定義すると, 系 $\Sigma_{1}$ はつぎの発展方程式により記述さ れる13).

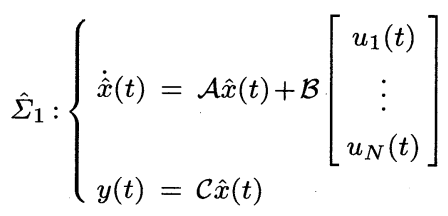

$$
\begin{aligned}
& \hat{x}(t)=\left[\begin{array}{c}
x(t) \\
u_{t}^{1} \\
\vdots \\
u_{t}^{N}
\end{array}\right], u_{t}^{i}(\beta):=u_{i}(t+\beta) \quad\left(-L_{i} \leq \beta \leq 0\right) \\
& (i=1,2, \cdots, N)
\end{aligned}
$$

ここで, 作用素 $\mathcal{A}$ は

$$
\begin{gathered}
\mathcal{A} \phi=\left[\begin{array}{c}
A \phi^{0}+\sum_{k=1}^{N} B_{k} \phi^{k}\left(-L_{k}\right) \\
\phi^{1 \prime} \\
\vdots \\
\phi^{N \prime}
\end{array}\right] \\
D(\mathcal{A})=\left\{\phi \in \mathcal{X}: \phi^{i} \in W^{1,2}\left(-L_{1}, 0 ; R^{m_{i}}\right)\right. \\
\left.\phi^{i}(0)=0,(i=1,2, \cdots, N)\right\}
\end{gathered}
$$

と定めた無限小生成作用素であり, 状態空間 $\mathcal{X}$ を $\mathcal{V}:=$ $D\left(\mathcal{A}^{*}\right)^{*}$ と拡張すると, 作用素 $\mathcal{A}$ の定義域は $D \mathcal{V}(\mathcal{A})=\mathcal{X}$ となる。また, 空間 $\mathcal{V}^{*} を \mathcal{V}^{*}:=D\left(\mathcal{A}^{*}\right)$ と定めると, $\mathcal{V}^{*}, \mathcal{X}, \mathcal{V}$ は $\mathcal{V}^{*} \subset \mathcal{X} \subset \mathcal{V}\left(\mathcal{X}=\mathcal{X}^{*}\right)$ と稠密に埋め込まれ ており, 入出力を表す作用素 $\mathcal{B}, \mathcal{C}$ は

$$
\begin{aligned}
& \mathcal{B}: R^{m} \rightarrow \mathcal{V}, \mathcal{B}^{*} \psi=\left[\begin{array}{c}
\psi^{1}(0) \\
\vdots \\
\psi^{N}(0)
\end{array}\right] \\
& \left(\psi \in \mathcal{V}^{*}=D\left(\mathcal{A}^{*}\right), m=m_{1}+m_{2}+\cdots+m_{N}\right) \\
& \mathcal{C}: \mathcal{X} \rightarrow R^{r}, \mathcal{C} \phi=C \phi^{0}(\phi \in \mathcal{X})
\end{aligned}
$$

と与えられる.ここで空間 $\mathcal{V}^{*}$ はV $\mathcal{V}$ に対して，Xでの

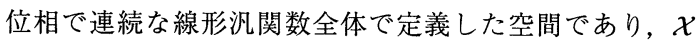
の位相に依存することに注意する。言い換えれば， $\psi \in \mathcal{V}$ としたとき，任意の $\phi \in \mathcal{V}^{*}$ に対して (2) 式右辺の演算が 有界であることが保証される。

\section{2 入力むだ時間系のグラミアンとハンケル特 異值}

可制御性グラミアンは入力と状態, 可観測性グラミア ンは状態と出力を対応させた作用素である。そして，八 ンケル作用素は入出力を直接対応させた作用素で, それ らの特異值と特異ベクトルは, 可制御性/可観測性グラミ アンの固有值問題から求めることができる.

ここでは, (3) 式の記述を用いて, ハンケル特異值の計 算に必要となる可制御性/可観測性グラミアンが代数方程 式の解から構成できることを示す。その後に，解析的に 求められたグラミアンからハンケル特異值の満たす条件 が導出できることを示す。

【定理 1】（入力むだ時間系のグラミアン）リアプノ 
フ作用素方程式

$$
\mathcal{A P} \psi+\mathcal{P} \mathcal{A}^{*} \psi+\mathcal{B B}^{*} \psi=0\left(\psi \in \mathcal{V}^{*}\right)
$$

を満たす可制御性グラミアン $\mathcal{P}>0(\mathcal{P} \in \mathcal{L}(\mathcal{X}))$ は,

$$
A P+P A^{\mathrm{T}}+B B^{\mathrm{T}}=0
$$

の正定解 $P=: G G^{\mathrm{T}}$ を用いて, つぎのように与えられる.

$$
\mathcal{P}:=\mathcal{G} \mathcal{G}^{*}, \mathcal{G} v:=\left[\begin{array}{c}
G v^{0} \\
v^{1} \\
\vdots \\
v^{N}
\end{array}\right](\mathcal{G} \in \mathcal{L}(\mathcal{X}), v \in \mathcal{X})
$$

また,つぎのリアプノフ作用素方程式

$$
\mathcal{M} \mathcal{A} \phi+\mathcal{A}^{*} \mathcal{M} \phi+\mathcal{C}^{*} \mathcal{C} \phi=0(\phi \in \mathcal{X})
$$

を満たす可観測性グラミアン $\mathcal{M}>0\left(\mathcal{M} \in \mathcal{L}\left(\mathcal{V}, \mathcal{V}^{*}\right)\right)$ は,

$$
M A+A^{\mathrm{T}} M+C^{\mathrm{T}} C=0
$$

の正定解 $M=: F^{\mathrm{T}} F$ を用いて，つぎのように与えられる.

$$
\mathcal{M}:=\mathcal{F}^{*} \mathcal{F}
$$

ここで $\mathcal{F} \in \mathcal{L}\left(\mathcal{X}, R^{n} \times L_{2}\left(-L_{1}, 0 ; R^{r}\right)\right)$ は，つぎのよう に定めた作用素である。

$$
\begin{aligned}
& {\left[\begin{array}{c}
(\mathcal{F} v)^{0} \\
(\mathcal{F} v)^{1}(\xi)
\end{array}\right]:=\left[\begin{array}{c}
F e^{A L_{1}} v^{0} \\
C e^{A\left(\xi+L_{1}\right)} v^{0}
\end{array}\right.} \\
& +\left(\sum_{i=1}^{N} \int_{-L_{i}}^{0} F e^{-A\left(\beta+L_{i}-L_{1}\right)} B_{i} v^{i}(\beta) \mathrm{d} \beta\right) \\
& +\int_{-L_{1}}^{\xi} C e^{A(\xi-\beta)} r(\beta) \mathrm{d} \beta \\
& r(\beta)=\sum_{k=1}^{i} B_{k} v^{k}\left(\beta+L_{1}-L_{k}\right) \\
& \left(v \in \mathcal{X},-L_{1}+L_{i+1} \leq \beta<-L_{1}+L_{i}\right)
\end{aligned}
$$

（証明）可制御性グラミアンが (5) 式の解であること は, (7) 式を (5) 式に直接代入することにより確認でき る. また, 可観測性グラミアンが (8) 式の解であること は, (10), (11) 式を (8) 式に代入し

$$
\begin{array}{r}
\langle\mathcal{F} \psi, \mathcal{F} \mathcal{A} \phi\rangle+\langle\mathcal{F} \mathcal{A} \psi, \mathcal{F} \phi\rangle+\langle\mathcal{C} \psi, \mathcal{C} \phi\rangle=0 \\
\phi, \psi \in D(\mathcal{A})
\end{array}
$$

を確認することにより証明できる。
以上の計算により, 可制御性/可観測性グラミアンが導 出できた。つきに,これらを用いたハンケル特異值の計 算法を示す.

ハンケル特異值 $\sigma>0$ は, 定理 1 により求められた作 用素 $\mathcal{G}, \mathcal{F}$ を用いて与えられ, ハンケル特異值 $\sigma$ と特異 ベクトル $(u, v) \neq 0$ が

$$
\sigma u=\mathcal{F} \mathcal{G} v, \sigma v=\mathcal{G}^{*} \mathcal{F}^{*} u
$$

なる条件を満たすことを用いると，計算法はつぎのよう に整理できる。

【定理 2】（ハンケル特異值）系 $\Sigma_{1}$ のハンケル特異 值 $\sigma$ は超越方程式

$$
\begin{aligned}
& \operatorname{det}(X)=0 \\
& X=\left[\begin{array}{lll}
-\sigma^{-1} M & I_{n}
\end{array}\right] e^{J_{1}\left(L_{1}-L_{2}\right)} e^{J_{2}\left(L_{2}-L_{3}\right)} \times \cdots \\
& \cdots \times e^{J_{N} L_{N}}\left[\begin{array}{c}
\sigma^{-1} P \\
I_{n}
\end{array}\right] \\
& J_{i}:=\left[\begin{array}{cc}
A & \sigma^{-1}\left(B_{1} B_{1}^{\mathrm{T}}+\cdots+B_{i} B_{i}^{\mathrm{T}}\right) \\
-\sigma^{-1} C^{\mathrm{T}} C & -A^{\mathrm{T}}
\end{array}\right]
\end{aligned}
$$

の根により与えられる. また, 特異ベクトル $u=\left(u^{0}, u^{1}\right)$ $\in R^{n} \times L_{2}\left(-L_{1}, 0 ; R^{r}\right), v=\left(v^{0}, v^{1}, \cdots, v^{N}\right) \in \mathcal{X}$ は $X g=$ 0 となるべクトル $g \neq 0\left(g \in R^{n}\right)$ と $(6),(9)$ 式の解 $P=$ $G G^{\mathrm{T}}, M=F^{\mathrm{T}} F$ を用いて, つぎのように構成できる.

$$
\begin{aligned}
& v^{0}=G^{\mathrm{T}} g \\
& v^{i}(\beta)=\left[\begin{array}{ll}
0 & B_{i}^{\mathrm{T}}
\end{array}\right] \Pi\left(\beta-L_{1}+L_{i}\right) \\
& u^{0}=\left[\begin{array}{ll}
F & 0
\end{array}\right] \Pi(0) \\
& u^{1}(\beta)=\left[\begin{array}{ll}
C & 0
\end{array}\right] \Pi(\beta) \\
& \Pi(\beta):=e^{J_{i}\left(\beta+L_{1}-L_{i+1}\right)} e^{J_{i+1}\left(L_{i+1}-L_{i+2}\right)} \times \cdots \\
& \cdots \times e^{J_{N} L_{N}}\left[\begin{array}{c}
\sigma^{-1} P \\
I_{n}
\end{array}\right] g
\end{aligned}
$$

$$
-L_{1}+L_{i+1}<\beta \leq-L_{1}+L_{i}, L_{N+1}=0
$$

（証明）ハンケル特異值 $\sigma>0$ と対応する特異ベクト ル $u, v$ は $(14)$ 式を満たす. 以下では, 作用素 $\mathcal{F G}$ の特 異值すべてが (15) 式の根に一致することを示す. (14) 式 に補助変数

$$
\begin{aligned}
& p(\xi)=e^{A\left(\xi+L_{1}\right)} G v^{0}+\int_{-L_{1}}^{\xi} e^{A(\xi-\beta)} r(\beta) \mathrm{d} \beta \\
& (r(\beta) \text { は (12) 式で定義) }
\end{aligned}
$$




$$
q(\beta)=e^{-A^{\mathrm{T}} \beta} F^{\mathrm{T}} u^{0}+\int_{\beta}^{0} e^{A^{\mathrm{T}}(\xi-\beta)} C^{\mathrm{T}} u^{1}(\xi) \mathrm{d} \xi(22)
$$

を導入し,これらを整理すると以下の関係が得られる。

$$
\begin{aligned}
\sigma u^{0}= & F p(0) \\
\sigma u^{1}(\xi)= & C p(\xi) \\
p\left(-L_{1}\right)= & G v^{0} \\
\frac{\mathrm{d}}{\mathrm{d} \xi} p(\xi)= & A p(\xi)+\sum_{k=1}^{i} B_{k} v^{k}\left(\xi+L_{1}-L_{k}\right) \\
& \left(-L_{1}+L_{i+1} \leq \xi<-L_{1}+L_{i}\right) \\
\sigma v^{0}= & G^{\mathrm{T}} q\left(-L_{1}\right) \\
\sigma v^{i}(\beta)= & B_{i}^{\mathrm{T}} q\left(\beta-L_{1}+L_{i}\right) \\
q(0)= & F^{\mathrm{T}} u^{0} \quad(i=1,2, \cdots, N) \\
\frac{\mathrm{d}}{\mathrm{d} \beta} q(\beta)= & -A^{\mathrm{T}} q(\beta)-C^{\mathrm{T}} u^{1}(\beta)
\end{aligned}
$$

つぎに $(24),(28)$ 式を(26), (30) 式に代入すると,

$$
\begin{aligned}
& {\left[\begin{array}{c}
p^{\prime}(\beta) \\
q^{\prime}(\beta)
\end{array}\right]=\left[\begin{array}{c}
A p(\beta)+\sigma^{-1}\left(\sum_{k=1}^{i} B_{k} B_{k}^{\mathrm{T}}\right) q(\beta) \\
-\sigma^{-1} C^{\mathrm{T}} C p(\beta)-A^{\mathrm{T}} q(\beta)
\end{array}\right]} \\
& \left(-L_{1}+L_{i+1} \leq \beta<-L_{1}+L_{i}\right)
\end{aligned}
$$

すなわち，

$$
\begin{array}{r}
{\left[\begin{array}{l}
p(0) \\
q(0)
\end{array}\right]=e^{J_{1}\left(L_{1}-L_{2}\right)} e^{J_{2}\left(L_{2}-L_{3}\right)} \times \cdots} \\
\cdots \times e^{J_{N} L_{N}}\left[\begin{array}{l}
p\left(-L_{1}\right) \\
q\left(-L_{1}\right)
\end{array}\right]
\end{array}
$$

が得られ，(23)，(25)，(27)，(29) 式からは境界条件

$$
p\left(-L_{1}\right)=\sigma^{-1} P q\left(-L_{1}\right), q(0)=\sigma^{-1} M p(0)
$$

が導かれる.したがって特異值 $\sigma$ に対する特異ベクトル $u, v$ が存在するためには, $\sigma$ が $(15)$ 式の解であることが 必要である.

十分性は， $\sigma$ を(15) 式の根としたとき, 代数ベクトル $g \neq 0$ から特異ベクトルが構成できることで示される.

以上の結果により, 複数の入力むだ時間が独立したチャ ネルに存在する系に対して, ハンケル特異値と特異ベク トルを求めることができる.

\section{3. 一方向性むだ時間系}

ここでは Fig. 2 のように表された一方向性むだ時間系 に注目し, ハンケル特異值と特異ベクトルの計算法を考 察する.そして,これらの計算が 2. の結果を利用して行

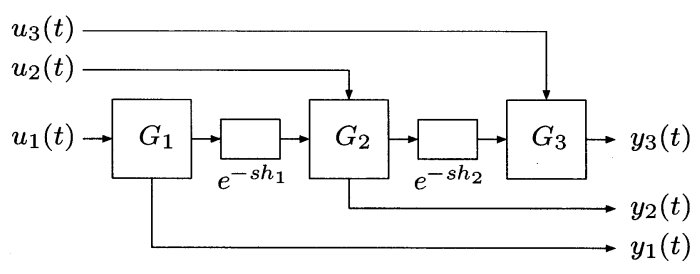

Fig. 2 Unilateral time delay system $(N=2)$

えることを明らかにする．

以下では,はじめに一方向性むだ時間系の記述を整理 し， 2 種類の補助系を導入する。つぎにこれらの補助系 と定理 1 を用いると, 一方向性むだ時間系の可制御性 . 可観測性グラミアンが構成できることを示し，ハンケル 特異值・特異ベクトルの計算法を明らかにする.

\section{1 一方向性むだ時間系の記述}

長さが $h_{1}, h_{2}, \cdots, h_{N}$ のむだ時間要素で結合された一 方向性むだ時間系を考える (Fig. 2) .

$$
\Sigma_{2}:\left\{\begin{aligned}
\dot{x}(t)= & A_{U} x(t)+D_{2} z_{1}\left(t-h_{1}\right) \\
& +D_{3} z_{2}\left(t-h_{2}\right)+\cdots \\
& \cdots+D_{N+1} z_{N}\left(t-h_{N}\right)+B_{U} u(t)(34) \\
z_{i}(t)= & E_{i} x(t)(i=1,2, \cdots, N) \\
y(t)= & C_{U} x(t)
\end{aligned}\right.
$$

$$
\begin{aligned}
& x(t)=\left[\begin{array}{llll}
x_{1}^{\mathrm{T}}(t) & x_{2}^{\mathrm{T}}(t) & \cdots & x_{N+1}^{\mathrm{T}}(t)
\end{array}\right]^{\mathrm{T}} \in R^{n} \\
& u(t)=\left[\begin{array}{lllll}
u_{1}^{\mathrm{T}}(t) & u_{2}^{\mathrm{T}}(t) & \cdots & u_{N+1}^{\mathrm{T}}(t)
\end{array}\right]^{\mathrm{T}} \in R^{m} \\
& y(t)=\left[\begin{array}{llll}
y_{1}^{\mathrm{T}}(t) & y_{2}^{\mathrm{T}}(t) & \cdots & y_{N+1}^{\mathrm{T}}(t)
\end{array}\right]^{\mathrm{T}} \in R^{r} \\
& x_{i}(t) \in R^{n_{i}}, u_{i}(t) \in R^{m_{i}}, y_{i}(t) \in R^{r_{i}} \\
& (i=1,2, \cdots, N+1) \\
& z_{i}(t) \in R^{p_{i}},(i=1,2, \cdots, N) \\
& A_{U}=\operatorname{diag}\left(A_{1}, A_{2}, \cdots, A_{N+1}\right) \\
& B_{U}=\left[\begin{array}{llll}
\hat{B}_{1} & \hat{B}_{2} & \cdots & \hat{B}_{N+1}
\end{array}\right] \\
& \hat{B}_{i}=\left[\begin{array}{llllllll}
0^{\mathrm{T}} & \cdots & 0^{\mathrm{T}} & \tilde{B}_{i}^{\mathrm{T}} & 0^{\mathrm{T}} & \cdots & 0^{\mathrm{T}}
\end{array}\right]^{\mathrm{T}} \\
& C_{U}=\left[\begin{array}{llll}
\hat{C}_{1}^{\mathrm{T}} & \hat{C}_{2}^{\mathrm{T}} & \cdots & \hat{C}_{N+1}^{\mathrm{T}}
\end{array}\right]^{\mathrm{T}} \\
& \hat{C}_{j}=\left[\begin{array}{lllllll}
0 & \cdots & 0 & \tilde{C}_{j} & 0 & \cdots & 0
\end{array}\right] \\
& D_{i}=\left[\begin{array}{lllllll}
0^{\mathrm{T}} & \cdots & 0^{\mathrm{T}} & \tilde{D}_{i}^{\mathrm{T}} & 0^{\mathrm{T}} & \cdots & 0^{\mathrm{T}}
\end{array}\right]^{\mathrm{T}} \\
& E_{j}=\left[\begin{array}{lllllll}
0 & \cdots & 0 & \tilde{E}_{j} & 0 & \cdots & 0
\end{array}\right]
\end{aligned}
$$

ここで, $\left(C_{U}, A_{U}, B_{U}\right)$ は可観測, 可制御, 行列 $A_{U}$ は 安定であるとする.

系 $\Sigma_{2}$ は状態空間を 


$$
\begin{aligned}
\mathcal{X}_{U}:= & R^{n} \times L_{2}\left(-h_{1}, 0 ; R^{p_{1}}\right) \\
& \times L_{2}\left(-h_{2}, 0 ; R^{p_{2}}\right) \times \cdots \times L_{2}\left(-h_{N}, 0 ; R^{p_{N}}\right)
\end{aligned}
$$

と選ぶと,つぎの発展方程式により記述される13).

$$
\begin{aligned}
& \hat{\Sigma}_{2}:\left\{\begin{array}{c}
\dot{\hat{x}}_{U}(t)=\mathcal{A}_{U} \hat{x}_{U}(t)+\mathcal{B}_{U} u(t) \\
y(t)=\mathcal{C}_{U} \hat{x}_{U}(t)
\end{array}\right. \\
& \hat{x}_{U}(t)=\left[\begin{array}{c}
x(t) \\
z_{t}^{1} \\
\vdots \\
z_{t}^{N}
\end{array}\right] \\
& z_{t}^{i}(\beta):=z_{i}(t+\beta)\left(-h_{i} \leq \beta \leq 0\right)(i=1,2, \cdots, N)
\end{aligned}
$$

ここで, 作用素 $\mathcal{A}_{U}$ は

$$
\mathcal{A}_{U} \phi_{U}=\left[\begin{array}{c}
A_{U} \phi_{U}^{0}+\sum_{k=1}^{N} D_{k+1} \phi_{U}^{k}\left(-h_{k}\right) \\
\phi_{U}^{1 \prime} \\
\vdots \\
\phi_{U}^{N \prime}
\end{array}\right]
$$

$$
\begin{gathered}
D\left(\mathcal{A}_{U}\right)=\left\{\phi_{U} \in \mathcal{X}_{U}: \phi_{U}^{i} \in W^{1,2}\left(-h_{i}, 0 ; R^{p_{i}}\right),\right. \\
\left.\phi_{U}^{i}(0)=E_{i} \phi_{U}^{0},(i=1,2, \cdots, N)\right\}
\end{gathered}
$$

と定めた無限小生成作用素であり, 入出力を表す作用素 $\mathcal{B}_{U}, \mathcal{C}_{U}$ は

$$
\begin{aligned}
\mathcal{B}_{U}: R^{m} \rightarrow \mathcal{X}_{U}, \mathcal{B}_{U} v & =\left[\begin{array}{c}
B_{U} v \\
0 \\
\vdots \\
0
\end{array}\right]\left(v \in R^{m}\right) \\
\mathcal{C}_{U}: \mathcal{X}_{U} \rightarrow R^{r}, \mathcal{C}_{U} \phi_{U} & =C_{U} \phi_{U}^{0}\left(\phi_{U} \in \mathcal{X}_{U}\right)
\end{aligned}
$$

と与えられる.

一方向性むだ時間系は, 個々の入出力間の伝達関数が 入力むだ時間系になり, 2 . で論じたむだ時間系と類似の 性質をもつことが期待される．以下では系 $\hat{\Sigma}_{2}$ に対して 2 種類の補助系を導入すると, 可制御性・可観測性グラ ミアンが定理 1 に基づいて構成できることを示す.

3.2 一方向性むだ時間系の可制御性グラミアン 系 $\hat{\Sigma}_{2}$ に対する可制御性グラミアンを求めるために, 入力にむだ時間を有する補助系を導入する. そして, 系 の入力・状態の関係を調べ, 可制御性グラミアンが定理

1 に基づいて構成できることを明らかにする.

系 $\Sigma_{1}$ と同じ構造をもつつぎの補助系を定義する.

$$
\Sigma_{3}:\left\{\begin{array}{l}
\dot{x}(t)=A_{I} x(t)+\hat{B}_{1} u_{1}\left(t-L_{1}\right) \\
+\hat{B}_{2} u_{2}\left(t-L_{2}\right)+\cdots \\
\cdots+\hat{B}_{N} u_{N}\left(t-L_{N}\right)+\hat{B}_{N+1} u_{N+1}(t)
\end{array}\right.
$$

$$
\begin{aligned}
& A_{I}=A_{U}+D_{2} E_{1}+D_{3} E_{2}+\cdots+D_{N+1} E_{N} \\
& x(t) \in R^{n} . u_{i}(t) \in R^{m_{i}}(i=1,2, \cdots, N+1)
\end{aligned}
$$

ここで, $L_{1}, L_{2}, \cdots, L_{N}$ はむだ時間の長さを表し, 系 $\Sigma_{2}$ のむだ時間 $h_{1}, h_{2}, \cdots, h_{N}$ に対して $L_{i}=\sum_{k=i}^{N} h_{k}$ と定める. 一方向性むだ時間系の定義から, $\left(A_{I}, B_{U}\right)$ は可制御, 行 列 $A_{I}$ は安定である.

系 $\Sigma_{3}$ は状態空間を

$$
\begin{aligned}
\mathcal{X}_{I}:= & R^{n} \times L_{2}\left(-L_{1}, 0 ; R^{m_{1}}\right) \\
& \times L_{2}\left(-L_{2}, 0 ; R^{m_{2}}\right) \times \cdots \times L_{2}\left(-L_{N}, 0 ; R^{m_{N}}\right)
\end{aligned}
$$

と選ぶと, つぎの発展方程式により記述される13).

$$
\hat{\Sigma}_{3}:\left\{\dot{\hat{x}}_{I}(t)=\mathcal{A}_{I} \hat{x}_{I}(t)+\mathcal{B}_{I}\left[\begin{array}{c}
u_{1}(t) \\
\vdots \\
u_{N+1}(t)
\end{array}\right]\right.
$$

$$
\hat{x}_{I}(t)=\left[\begin{array}{c}
x(t) \\
u_{t}^{1} \\
\vdots \\
u_{t}^{N}
\end{array}\right]
$$

$$
u_{t}^{i}(\beta):=u_{i}(t+\beta)\left(-L_{i} \leq \beta \leq 0\right) \quad(i=1,2, \cdots, N)
$$

ここで, 作用素 $\mathcal{A}_{I}$ は

$$
\begin{aligned}
\mathcal{A}_{I} \phi_{I}= & {\left[\begin{array}{c}
A_{I} \phi_{I}^{0}+\sum_{k=1}^{N} \hat{B}_{k} \phi_{I}^{k}\left(-L_{k}\right) \\
\phi_{I}^{1 \prime} \\
\vdots \\
\phi_{I}^{N \prime}
\end{array}\right] } \\
D\left(\mathcal{A}_{I}\right)= & \left\{\phi_{I} \in \mathcal{X}_{I}: \phi_{I}^{i} \in W^{1,2}\left(-L_{i}, 0 ; R^{m_{i}}\right),\right. \\
& \left.\phi_{I}^{i}(0)=0,(i=1,2, \cdots, N)\right\}
\end{aligned}
$$

と定めた無限小生成作用素であり, 状態空間 $\mathcal{X}_{I}$ を $\mathcal{V}_{I}:=D\left(\mathcal{A}_{I}^{*}\right)^{*}$ と拡張すると, 作用素 $\mathcal{A}_{I}$ の定義域は $D_{\mathcal{V}_{I}}\left(\mathcal{A}_{I}\right)=\mathcal{X}_{I}$ となる. 空間 $\mathcal{V}_{I}^{*}, \mathcal{X}_{I}, \mathcal{V}_{I}$ は $\mathcal{V}_{I}^{*} \subset \mathcal{X}_{I} \subset$ $\mathcal{V}_{I}\left(\mathcal{X}_{I}=\mathcal{X}_{I}^{*}\right)$ と稠密に埋め込まれており, 入力を表す作 用素 $\mathcal{B}_{I}$ は

$$
\mathcal{B}_{I}: R^{m} \rightarrow \mathcal{V}_{I}
$$




$$
\mathcal{B}_{I}^{*} \psi_{I}=\left[\begin{array}{c}
\psi_{I}^{1}(0) \\
\vdots \\
\psi_{I}^{N}(0) \\
\hat{B}_{N+1}^{\mathrm{T}} \psi_{I}^{0}
\end{array}\right]\left(\psi_{I} \in \mathcal{V}_{I}^{*}=D\left(\mathcal{A}_{I}^{*}\right)\right)
$$

と与えられる. 以上により，一方向性むだ時間系 $\hat{\Sigma}_{2}$ と 補助系 $\hat{\Sigma}_{3}$ が定義された。つぎに, これらの関係を整理 する。

系 $\hat{\Sigma}_{2}$ と $\hat{\Sigma}_{3}$ に共通の入力 $u \in L_{2}\left(-\infty, 0 ; R^{m}\right)$ を与え たとき, 0 から遷移するそれぞれの初期状態 $\hat{x}_{U}(0), \hat{x}_{I}(0)$ の対応を調べる. いま, 入力 $u \in L_{2}\left(-\infty, 0 ; R^{m}\right) に よ り$, 系 $\hat{\Sigma}_{3}$ の状態が $\hat{x}_{I}(0)=\phi_{I}$ に遷移したとする。 このとき, Fig. 3 に基づいて, 系の構造を部分的に変化させるとつ ぎの関係が明らかになる。

1) $G_{1}^{(a)}$ にむだ時間要素 $D_{11}^{(a)}, D_{12}^{(a)}$ に蓄えられていた 入力を印加すると, $G_{1}^{(b)}$, すなわち $G_{1}^{(c)}$ の内部状 態が求められる.また, この時発生した $G_{1}^{(a)}$ の出 力が, むだ時間要素 $D_{11}^{(b)}, D_{12}^{(b)}$ に蓄えられる.

2) $G_{2}^{(b)}$ にむだ時間要素 $D_{12}^{(b)}, D_{22}^{(a)}$ に蓄えられていた 入力を印加すると, $G_{2}^{(c)}$ の内部状態が求められる. また, この時発生した $G_{2}^{(b)}$ の出力が, むだ時間要 素 $D_{22}^{(c)}$ に蓄えられる.

したがって, サブシステムとむだ時間要素の順序を入 れ換え, 部分的に対応する状態と出力の関係を整理する とつぎの結果が求められる(証明略)。

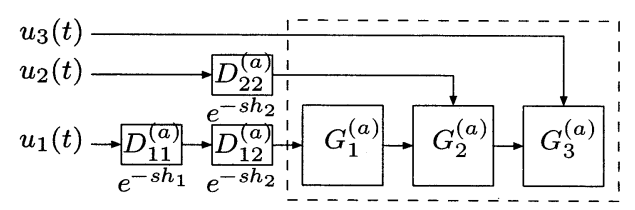

(a)

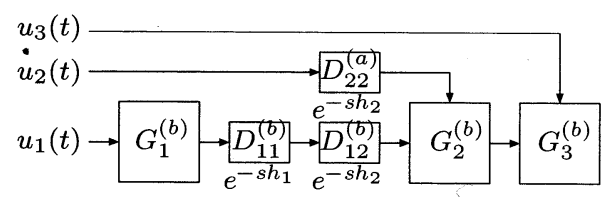

(b)

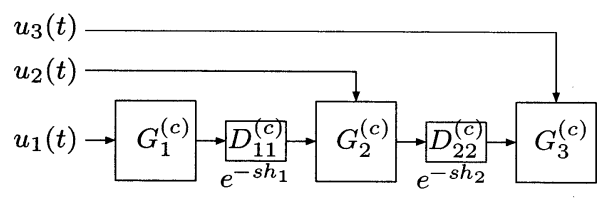

(c)

Fig. 3 Rearrange system (input time delay system, $N=$ 2)
【補題 1】系 $\hat{\Sigma}_{2}$ と $\hat{\Sigma}_{3}$ に共通の入力 $u \in L_{2}(-\infty$, $\left.0 ; R^{m}\right)$ を与え，それぞれの状態が 0 から $\hat{x}_{U}(0)=\phi_{U}$, $\hat{x}_{I}(0)=\phi_{I}$ に遷移したとする。このとき, 状態 $\phi_{U}$ と $\phi_{I}$ の関倸は, 作用素 $\mathcal{T}_{U I} \in \mathcal{L}\left(\mathcal{X}_{I}, D\left(\mathcal{A}_{U}\right)\right)$ を用いてつぎ のように表される。

$$
\begin{aligned}
& \phi_{U}^{0}=\left(\mathcal{T}_{U I} \phi_{I}\right)^{0}:=e^{U_{1} A_{I} h_{1}+U_{2} A_{I} h_{2}+\cdots+U_{N} A_{I} h_{N}} \phi_{I}^{0} \\
& +\sum_{j=1}^{N} \int_{-L_{j}}^{0} \hat{U}_{j} e^{-A_{I} \beta}\left(\sum_{k=1}^{j} \hat{B}_{k} \phi_{I}^{k}\left(\beta-L_{k}+L_{j}\right)\right) \mathrm{d} \beta(40) \\
& \phi_{U}^{i}=\left(\mathcal{T}_{U I} \phi_{I}\right)^{i}(\xi):=E_{i} e^{A_{I}\left(\xi+L_{i}\right)} \phi_{I}^{0} \\
& +\int_{-L_{i}}^{\xi} E_{i} e^{A_{I}(\xi-\beta)}\left(\sum_{k=1}^{i} \hat{B}_{k} \phi_{I}^{k}\left(\beta-L_{k}+L_{i}\right)\right) \mathrm{d} \beta \\
& \left(\mathcal{T}_{U I} \phi_{I}\right)^{i}(0)=E_{i}\left(\mathcal{T}_{U I} \phi_{I}\right)^{0}(i=1,2, \cdots, N) \\
& \phi_{I} \in \mathcal{X}_{I} \\
& U_{i}=\left[\begin{array}{cc}
I_{n_{1}+\cdots+n_{i}} & 0 \\
0 & 0_{n_{i+1}+\cdots+n_{N}}
\end{array}\right] \in R^{n \times n} \\
& \hat{U}_{i}=\left[\begin{array}{ccc}
0_{n_{1}+\cdots+n_{i-1}} & 0 & 0 \\
0 & I_{n_{i}} & 0 \\
0 & 0 & 0_{n_{i+1}+\cdots+n_{N}}
\end{array}\right] \in R^{n \times n}
\end{aligned}
$$

さらに, 作用素 $\mathcal{A}_{I}, \mathcal{A}_{U}$ と $\mathcal{B}_{I}, \mathcal{B}_{U}$ の関係が

$$
\begin{aligned}
\mathcal{T}_{U I} \mathcal{A}_{I} \phi_{I} & =\mathcal{A}_{U} \mathcal{T}_{U I} \phi_{I}\left(\phi_{I} \in D\left(\mathcal{A}_{I}\right)\right) \\
\mathcal{B}_{I}^{*} \mathcal{T}_{U I}^{*} \psi_{U} & =\mathcal{B}_{U}^{*} \psi_{U}\left(\psi_{U} \in \mathcal{X}_{U}\right)
\end{aligned}
$$

と与えられる。

以上のように状態空間 $\mathcal{X}_{U}, \mathcal{X}_{I}$ を定め, これらの関倸 を作用素 $\mathcal{T}_{U I}$ で表すと，一方向性むだ時間系の可制御性 グラミアンはつぎのように求まる.

【補題 2】リアプノフ作用素方程式

$$
\begin{aligned}
& \mathcal{A}_{U} \mathcal{P}_{U} \psi_{U}+\mathcal{P}_{U} \mathcal{A}_{U}^{*} \psi_{U}+\mathcal{B}_{U} \mathcal{B}_{U}^{*} \psi_{U}=0 \\
& \left(\psi_{U} \in \mathcal{V}_{U}^{*}\right)
\end{aligned}
$$

を满たす可制御性グラミアン $\mathcal{P}_{U}>0\left(\mathcal{P}_{U} \in \mathcal{L}\left(\mathcal{X}_{U}\right)\right)$ は,

$$
A_{I} P_{I}+P_{I} A_{I}^{\mathrm{T}}+B_{U} B_{U}^{\mathrm{T}}=0
$$

の正定解 $P_{I}=: G_{I} G_{I}^{\mathrm{T}}$ と (40), (41) 式を用いて,つぎの ように与えられる。

$$
\mathcal{P}_{U}:=\mathcal{T}_{U I} \mathcal{G}_{I} \mathcal{G}_{I}^{*} \mathcal{T}_{U I}^{*}, \mathcal{G}_{I} v:=\left[\begin{array}{c}
G_{I} v^{0} \\
v^{1} \\
\vdots \\
v^{N}
\end{array}\right]
$$


$\mathcal{G}_{I} \in \mathcal{L}\left(\mathcal{X}_{I}\right), v \in \mathcal{X}_{I}$

(証明) $\mathcal{P}_{I}:=\mathcal{G}_{I} \mathcal{G}_{I}^{*}$ とすると, 系 $\hat{\Sigma}_{3}$ の定義と定理 1 からつぎのようなリアプノフ作用素方程式が与えられる.

$$
\mathcal{A}_{I} \mathcal{P}_{I} \psi_{I}+\mathcal{P}_{I} \mathcal{A}_{I}^{*} \psi_{I}+\mathcal{B}_{I} \mathcal{B}_{I}^{*} \psi_{I}=0\left(\psi_{I} \in \mathcal{V}_{I}^{*}\right)
$$

この式の左右から $\mathcal{T}_{U I}, \mathcal{T}_{U I}^{*}$ を作用させ, (42), (43) 式 の関係を用いると，(44) 式が得られる.よって $\mathcal{P}_{U}=$ $\mathcal{T}_{U I} \mathcal{P}_{I} \mathcal{T}_{U I}^{*}$ は (44) 式の解となる.

3.3 一方向性むだ時間系の可観測性グラミアン

つぎに，系 $\hat{\Sigma}_{2}$ に対する可観測性グラミアンを求める ために，出力にむだ時間を有する補助系を導入する。そ して, 系の出力・状態の関係を調べ, 可観測性グラミア ンが定理 1 に基づいて構成できることを明らかにする. 系 $\Sigma_{1}$ と双対な構造をもつつぎの補助系を定義する.

$$
\Sigma_{4}:\left\{\begin{aligned}
\dot{x}(t) & =A_{I} x(t) \\
y_{1}(t) & =\hat{C}_{1} x(t) \\
y_{2}(t) & =\hat{C}_{2} x\left(t-L_{1}+L_{2}\right) \\
& \vdots \\
y_{N+1}(t) & =\hat{C}_{N+1} x\left(t-L_{1}+L_{N+1}\right)
\end{aligned}\right.
$$

$x(t) \in R^{n} \cdot y_{i}(t) \in R^{r_{i}}(i=1,2, \cdots, N+1)$

ここで, $L_{1}-L_{2}, L_{1}-L_{3}, \cdots, L_{1}-L_{N+1}$ はむだ時間の 長さを表し，系 $\Sigma_{2}$ のむだ時間 $h_{1}, h_{2}, \cdots, h_{N}$ に対して $L_{1}-L_{i}=\sum_{k=1}^{i-1} h_{k}$ と定める. 一方向性むだ時間系の定義 から, $\left(C_{U}, A_{I}\right)$ は可観測, 行列 $A_{I}$ は安定である.

系 $\Sigma_{4}$ は状態空間を

$$
\begin{aligned}
& \mathcal{X}_{O}:=R^{n} \times L_{2}\left(-L_{1}+L_{2}, 0 ; R^{r_{2}}\right) \\
& \times L_{2}\left(-L_{1}+L_{3}, 0 ; R^{r_{3}}\right) \times \cdots \\
& \cdots \times L_{2}\left(-L_{1}+L_{N+1}, 0 ; R^{r_{N+1}}\right), L_{N+1}:=0
\end{aligned}
$$

と選ぶと, つぎの発展方程式により記述される13).

$$
\begin{aligned}
& \hat{\Sigma}_{4}:\left\{\begin{array}{c}
\dot{\hat{x}}_{O}(t) \\
{\left[\begin{array}{c}
y_{1}(t) \\
\vdots \\
y_{N+1}(t)
\end{array}\right]=\mathcal{A}_{O} \hat{x}_{O}(t)}
\end{array}\right. \\
& \hat{x}_{O}(t)=\left[\begin{array}{c}
x(t) \\
\hat{C}_{2} x_{t} \\
\vdots \\
\hat{C}_{N+1} x_{t}
\end{array}\right] \\
& \hat{C}_{i} x_{t}(\beta):=\hat{C}_{i} x(t+\beta)\left(-L_{1}+L_{i} \leq \beta \leq 0\right)
\end{aligned}
$$

ここで，作用素 $\mathcal{A}_{O}$ は

$$
\begin{gathered}
\mathcal{A}_{O} \phi_{O}=\left[\begin{array}{c}
A_{I} \phi_{O}^{0} \\
\phi_{O}^{1 \prime} \\
\vdots \\
\phi_{O}^{N \prime}
\end{array}\right] \\
D\left(\mathcal{A}_{O}\right)=\left\{\phi_{O} \in \mathcal{X}_{O}:\right. \\
\phi_{O}^{i} \in W^{1,2}\left(-L_{1}+L_{i+1}, 0 ; R^{r_{i+1}}\right), \\
\left.\phi_{O}^{i}(0)=\hat{C}_{i+1} \phi_{O}^{0},(i=1,2, \cdots, N)\right\}
\end{gathered}
$$

と定めた無限小生成作用素であり, 状態空間 $\mathcal{X}_{O}$ を $\mathcal{W}_{O}:=D\left(\mathcal{A}_{O}\right)^{*}$ と拡張すると, 作用素 $\mathcal{A}_{O}^{*}$ の定義域が $D_{\mathcal{W}_{O}}\left(\mathcal{A}_{O}^{*}\right)=\mathcal{X}_{O}$ となる. 空間 $\mathcal{W}_{O}^{*}, \mathcal{X}_{O}, \mathcal{W}_{O}$ は $\mathcal{W}_{O}^{*} \subset$ $\mathcal{X}_{O} \subset \mathcal{W}_{O}\left(\mathcal{X}_{O}=\mathcal{X}_{O}^{*}\right)$ と稠密に埋め込まれており, 出力 を表す作用素 $\mathcal{C}_{O}$ は

$$
\begin{aligned}
& \mathcal{C}_{O}: D\left(\mathcal{A}_{O}\right) \rightarrow R^{r} \\
& \mathcal{C}_{O} \phi_{O}=\left[\begin{array}{c}
\hat{C}_{1} \phi_{O}^{0} \\
\phi_{O}^{1}\left(-L_{1}+L_{2}\right) \\
\vdots \\
\phi_{O}^{N}\left(-L_{1}+L_{N+1}\right)
\end{array}\right]\left(\phi_{O} \in D\left(\mathcal{A}_{O}\right)\right)
\end{aligned}
$$

と与えられる. 系 $\hat{\Sigma}_{4}$ は Fig. 1 に示した入力むだ時間系 に対して双対な構造を有している。したがって, 系 $\hat{\Sigma}_{4} に$ 対する可観測性グラミアンは, 作用素方程式 (5) 式に対 する解法に基づいて構成することができる．以上により， 補助系 $\hat{\Sigma}_{4}$ が定義された。つぎに，一方向性むだ時間系 との関係を整理する.

系 $\hat{\Sigma}_{4}$ の例として, $N=2$ の場合を Fig. 4 に示した. 系 $\hat{\Sigma}_{3}$ の場合と同様に，サブシステムとむだ時間要素の 順序を入れ換え, 部分的に対応する状態と出力の関係を 整理することで, $\hat{\Sigma}_{2}$ と $\hat{\Sigma}_{4}$ の関係が明らかになり,つぎ の結果が求められる(証明略).

【補題 3】系 $\hat{\Sigma}_{2}$ と $\hat{\Sigma}_{4}$ に初期状態 $\hat{x}_{U}(0)=\phi_{U}$, $\hat{x}_{O}(0)=\phi_{O}$ を与えたとき, 同一の出力 $y \in L_{2}\left(0, \infty ; R^{r}\right)$ が発生したとする.このとき, 状態 $\phi_{U}$ と $\phi_{O}$ の関係は, 作用素 $\mathcal{T}_{O U} \in \mathcal{L}\left(\mathcal{X}_{U}, D\left(\mathcal{A}_{O}\right)\right)$ を用いてつぎのように表

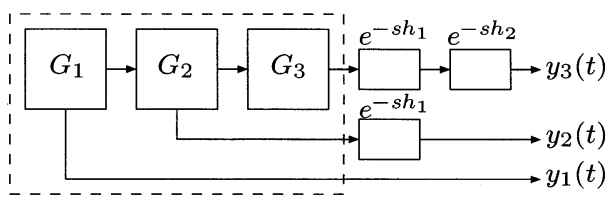

Fig. 4 Output time delay system $(N=2)$ 
される.

$\phi_{O}^{0}=\left(\mathcal{T}_{O U} \phi_{U}\right)^{0}:=e^{\bar{U}_{1} A_{I} h_{1}+\bar{U}_{2} A_{I} h_{2}+\cdots+\bar{U}_{N} A_{I} h_{N}} \phi_{U}^{0}$

$+\sum_{j=1}^{N} \int_{-h_{j}}^{0} \bar{U}_{j} e^{-A_{I} \beta} D_{j+1} \phi_{U}^{j}(\beta) \mathrm{d} \beta$

$\phi_{O}^{i}=\left(\mathcal{T}_{O U} \phi_{U}\right)^{i}(\xi):=\hat{C}_{i+1} e^{\bar{U}_{i} A_{I}\left(\xi+L_{1}-L_{i+1}\right)} \phi_{U}^{0}$

$+\sum_{k=i}^{j+1} \int_{-h_{k}}^{0} \hat{C}_{i+1} \bar{U}_{k} e^{-A_{I} \beta} D_{k+1} \phi_{U}^{k}(\beta) \mathrm{d} \beta$

$+\int_{-L_{1}+L_{j+1}}^{\xi} \hat{C}_{i+1} \bar{U}_{j} e^{A_{I}(\xi-\beta)} D_{j+1} \phi_{U}^{j}\left(\beta+L_{1}-L_{j}\right) \mathrm{d} \beta(52)$

$-L_{1}+L_{j+1} \leq \xi \leq-L_{1}+L_{j}$

$\left(\mathcal{T}_{O U} \phi_{U}\right)^{i}(0)=\hat{C}_{i+1}\left(\mathcal{T}_{O U} \phi_{U}\right)^{0}(i=1,2, \cdots, N)$

$\phi_{U} \in \mathcal{X}_{U}$

$\bar{U}_{i}=\left[\begin{array}{cc}0_{n_{1}+\cdots+n_{i}} & 0 \\ 0 & I_{n_{i+1}+\cdots+n_{N}}\end{array}\right] \in R^{n \times n}$

さらに, 作用素 $\mathcal{A}_{U}, \mathcal{A}_{O}$ と $\mathcal{C}_{U}, \mathcal{C}_{O}$ の関係が

$\mathcal{T}_{O U} \mathcal{A}_{U} \phi_{U}=\mathcal{A}_{O} \mathcal{T}_{O U} \phi_{U}$

$\mathcal{C}_{O} \mathcal{T}_{O U} \phi_{U}=\mathcal{C}_{U} \phi_{U}$

$\left(\phi_{U} \in D\left(\mathcal{A}_{U}\right)\right)$

と与えられる。

以上のように状態空間 $\mathcal{X}_{U}, \mathcal{X}_{O}$ を定め, これらの関係 を作用素 $\mathcal{T}_{O U}$ で表すと, 一方向性むだ時間系の可観測 性グラミアンはつぎのように求まる。

【補題 4】リアプノフ作用素方程式

$$
\begin{aligned}
& \mathcal{M}_{U} \mathcal{A}_{U} \phi_{U}+\mathcal{A}_{U}^{*} \mathcal{M}_{U} \phi_{U}+\mathcal{C}_{U}^{*} \mathcal{C}_{U} \phi_{U}=0 \\
& \left(\phi_{U} \in \mathcal{X}_{U}\right)
\end{aligned}
$$

を満たす可観測性グラミアン $\mathcal{M}_{U}>0 \quad\left(\mathcal{M}_{U} \in \mathcal{L}\left(\mathcal{V}_{U}\right.\right.$, $\left.\left.\mathcal{V}_{U}^{*}\right)\right)$ は,

$$
M_{O} A_{I}+A_{I}^{\mathrm{T}} M_{O}+C_{U}^{\mathrm{T}} C_{U}=0
$$

の正定解 $M_{O}=: F_{O}^{\mathrm{T}} F_{O}$ と (51), (52) 式を用いて, つぎ のように与えられる.

$$
\mathcal{M}_{U}:=\mathcal{T}_{O U}^{*} \mathcal{F}_{O}^{*} \mathcal{F}_{O} \mathcal{T}_{O U}, \mathcal{F}_{O} u:=\left[\begin{array}{c}
F_{O} u^{0} \\
u^{1} \\
\vdots \\
u^{N}
\end{array}\right]
$$

$\mathcal{F}_{O} \in \mathcal{L}\left(\mathcal{X}_{O}\right), u \in \mathcal{X}_{O}$

（証明）系 $\hat{\Sigma}_{3}$ と $\hat{\Sigma}_{4}$ は双対な関係にあるので, $\mathcal{M}_{O}:=$ $\mathcal{F}_{O}^{*} \mathcal{F}_{O}$ と置き, $\mathcal{A}_{I} \rightarrow \mathcal{A}_{O}^{*}, \mathcal{B}_{I} \rightarrow \mathcal{C}_{O}^{*}, \mathcal{P}_{I} \rightarrow \mathcal{M}_{O}$ の対 応をそれぞれ整理すると, 定理 1 からつぎのようなリア プノフ作用素方程式が与えられる。

$$
\mathcal{M}_{O} \mathcal{A}_{O} \phi_{O}+\mathcal{A}_{O}^{*} \mathcal{M}_{O} \phi_{O}+\mathcal{C}_{O}^{*} \mathcal{C}_{O} \phi_{O}=0
$$

$\left(\phi_{O} \in \mathcal{W}_{O}^{*}\right)$

この式の左右から $\mathcal{T}_{O U}^{*}, \mathcal{T}_{O U}$ を作用させ, (53), (54) 式 の関係を用いると, (55) 式が得られる。よって $\mathcal{M}_{U}=$ $\mathcal{T}_{O U}^{*} \mathcal{M}_{O} \mathcal{T}_{O U}$ は (55) 式の解となる.

以上の結果により, 補助系のグラミアンから本来の一 方向性むだ時間系のグラミアンが構成できることが示さ れた。

また，一方向性むだ時間系のリアプノフ代数方程式 (45), (56) が入力むだ時間系のリアプノフ代数方程式 (6) と同様なことから，入力むだ時間系と一方向性むだ時間 系が, “応答が一定時間後, 集中系の応答になる”という 同様の特徴をもっていることが確認できる.

\section{4 一方向性むだ時間系のハンケル特異值}

つぎに,グラミアンからハンケル特異值を導出する。 ハンケル特異值 $\sigma>0$ は, 補題 2,4 により求められた 作用素 $\mathcal{G}_{U}:=\mathcal{T}_{U I} \mathcal{G}_{I}, \mathcal{F}_{U}:=\mathcal{F}_{O} \mathcal{T}_{O U}$ を用いて与えられ, $\sigma$ と $(u, v)$ が

$$
\sigma u=\mathcal{F}_{U} \mathcal{G}_{U} v, \sigma v=\mathcal{G}_{U}^{*} \mathcal{F}_{U}^{*} u
$$

なる条件を満たすことを用いると, ハンケル特異值と特 異ベクトルの計算法はつぎのように整理できる.

【定理 3】（ハンケル特異值）系 $\Sigma_{2}$ のハンケル特異 值 $\sigma$ は超越方程式

$$
\begin{aligned}
& \operatorname{det}(X)=0 \\
& X=\left[\begin{array}{ll}
-\sigma^{-1} M_{O} & I_{n}
\end{array}\right] e^{\hat{J}_{1} h_{1}} e^{\hat{J}_{2} h_{2}} \times \cdots \\
& \cdots \times e^{\hat{J}_{N} h_{N}}\left[\begin{array}{c}
\sigma^{-1} P_{I} \\
I_{n}
\end{array}\right] \\
& \hat{J}_{i}:=\left[\begin{array}{cc}
A_{I} & \sigma^{-1} \sum_{k=1}^{i} \hat{B}_{k} \hat{B}_{k}^{\mathrm{T}} \\
-\sigma^{-1} \sum_{k=i+1}^{N+1} \hat{C}_{k}^{\mathrm{T}} \hat{C}_{k} & -A_{I}^{\mathrm{T}}
\end{array}\right]
\end{aligned}
$$

の根により与えられる. また, 特異べクトル $u=\left(u^{0}, u^{1}\right.$, $\left.\cdots, u^{N}\right) \in \mathcal{X}_{O}, v=\left(v^{0}, v^{1}, \cdots, v^{N}\right) \in \mathcal{X}_{I}$ は $X g=0$ となる 
ベクトル $g \neq 0\left(g \in R^{n}\right)$ と $(45),(56)$ 式の解 $P_{I}=G_{I} G_{I}^{\mathrm{T}}$, $M_{O}=F_{O}^{\mathrm{T}} F_{O}$ を用いて, つぎのように構成できる.

$$
\begin{aligned}
& v^{0}=G_{I}^{\mathrm{T}} g \\
& v^{i}(\beta)=\left[\begin{array}{ll}
0 & \hat{B}_{i}^{\mathrm{T}}
\end{array}\right] \Pi_{U}\left(\beta-L_{1}+L_{i}\right) \\
& u^{0}=\left[\begin{array}{ll}
F_{O} & 0
\end{array}\right] \Pi_{U}(0) \\
& u^{i}(\beta)=\left[\begin{array}{ll}
\hat{C}_{i+1} & 0
\end{array}\right] \Pi_{U}(\beta) \\
& (i=1,2, \cdots, N) \\
& \Pi_{U}(\beta):=e^{\hat{J}_{i}\left(\beta+L_{1}-L_{i+1}\right)} e^{\hat{J}_{i+1} h_{i+1}} \times \cdots \\
& \cdots \times e^{\hat{J}_{N} h_{N}}\left[\begin{array}{c}
\sigma^{-1} P_{I} \\
I_{n}
\end{array}\right] g \\
& -L_{1}+L_{i+1}<\beta \leq-L_{1}+L_{i}
\end{aligned}
$$

（証明）(59) 式を満たすハンケル特異值 $\sigma$ が存在する ためには, 作用素 $\mathcal{F}_{U} \mathcal{G}_{U}$ に対して導入された関数 $\Pi_{U}(\cdot)$ がつぎの微分方程式と境界条件

$$
\begin{aligned}
& \Pi_{U}^{\prime}(\beta)=\hat{J}_{i} \Pi_{U}(\beta) \\
& \left(-L_{1}+L_{i+1}<\beta \leq-L_{1}+L_{i}, i=1,2, \cdots, N\right) \\
& {\left[I_{n}-\sigma^{-1} P_{I}\right] \Pi_{U}\left(-L_{1}\right)=0} \\
& {\left[-\sigma^{-1} M_{O} I_{n}\right] \Pi_{U}(0)=0}
\end{aligned}
$$

を満たすことが必要十分である。

また, 特異べクトル $(u, v) \neq 0$ は微分方程式 (66) の解 を用いて構成できる。

定理 3 により，一方向性むだ時間系のハンケル特異值 と特異ベクトルの計算法が明らかになった。

\section{4. 平衡実現近似}

定理 2 と 定理 $\mathbf{3}$ により，入力むだ時間系と一方向性む だ時間系の特異值が超越方程式の根により与えられ，特 異ベクトルが常微分方程式の根から構成できることが明 らかになった。これらを用いると，平衡実現近似の計算 法はつぎのようにまとめられる.

【定理 4】（平衡実現近似）あるむだ時間系 $\Sigma$ に対 し, 平衡実現による $p$ 次の近似は

$$
\begin{aligned}
& \left\{\begin{array}{c}
\dot{x}_{p}(t)=A_{p} x_{N}(t)+B_{p} u(t) \\
y(t)=C_{p} x_{p}(t)
\end{array}\right. \\
& A_{p}:=\left[a_{i j}\right] \in R^{p \times p} \\
& B_{p}:=\left[b_{1}^{\mathrm{T}} \cdots b_{i}^{\mathrm{T}} \cdots b_{p}^{\mathrm{T}}\right]^{\mathrm{T}} \in R^{p \times m} \\
& C_{p}:=\left[c_{1} \cdots c_{j} \cdots c_{p}\right] \in R^{r \times p}
\end{aligned}
$$

$$
\begin{aligned}
& a_{i j}:=\frac{1}{\sqrt{\sigma_{i} \sigma_{j}}}\left\langle u_{i}, \mathcal{F} \mathcal{A} \mathcal{G} v_{j}\right\rangle \\
& b_{i}^{\mathrm{T}}:=\frac{1}{\sqrt{\sigma_{i}}} \mathcal{B}^{*} \mathcal{F}^{*} u_{i}, c_{j}:=\frac{1}{\sqrt{\sigma_{j}}} \mathcal{C} \mathcal{G} v_{j}
\end{aligned}
$$

と与えられる。ここで, $\sigma_{1}, \cdots, \sigma_{p}$ はハンケル特異值であ る. $v_{i}$ と $u_{i}$ は $\sigma_{i}$ に対応する作用素 $\mathcal{F G}$ の特異べクト ルで, $\left\langle v_{i}, v_{i}\right\rangle=1,\left\langle u_{i}, u_{i}\right\rangle=1$ と規格化したものである.

（略証）参考文献 1) の定理 3 と同様の計算を進めること により確認できる。

\section{5. 数值例}

入力むだ時間系 $\Sigma_{1}$ と一方向性むだ時間系 $\Sigma_{2}$ につい て，つぎのように各パラメータを定めた系に定理 4 を適 用して, 平衡実現近似を求める.

(1) 入力むだ時間系

$$
\begin{gathered}
y(s)=\left[\frac{1}{s+3} e^{-2 s} \frac{s+4}{(s+2)(s+3)} e^{-s}\right]\left[\begin{array}{l}
u_{1}(s) \\
u_{2}(s)
\end{array}\right] \\
\text { むだ時間 : } L_{1}=2.0, L_{2}=1.0 \text { 秒 }
\end{gathered}
$$

をそれぞれ 10,15, 20 次に近似し，得られた近似系の性 質を調べた（Figs. 5〜9）.

Figs. 5 7 は近似系の周波数応答である.Fig. 5 は $\sigma$ plot, Figs. 6, 7 はボード線図を表している. 低周波数帯 では良好な近似が得られているが, ある周波数で急激に ゲインが低下している。このことから，純粋なむだ時間 要素がもつ大きな位相遅れを近似できないような周波数 ではゲインが低下し，位相の誤差による影響が出力に現 れないような性質をもっていると考えられる。また，近

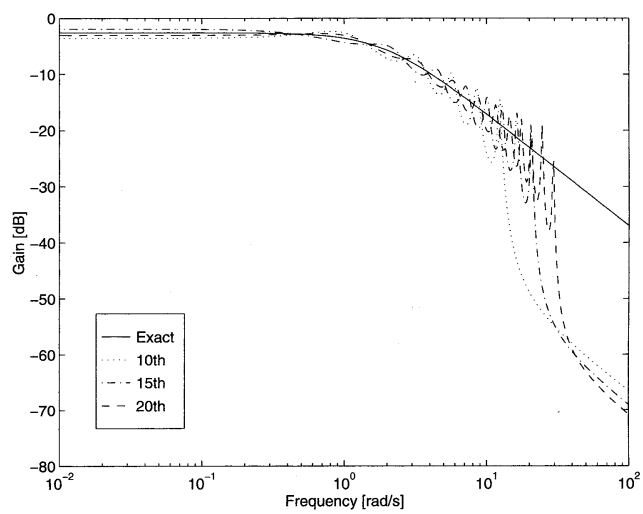

Fig. $5 \sigma$-plots of balanced reduction for an input time delay system 


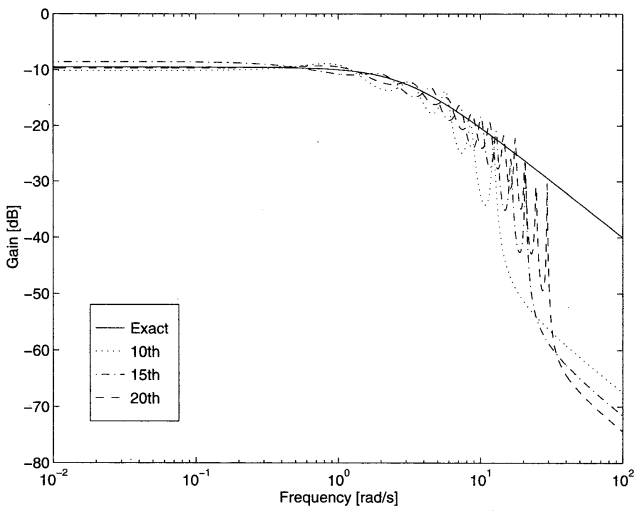

Gain

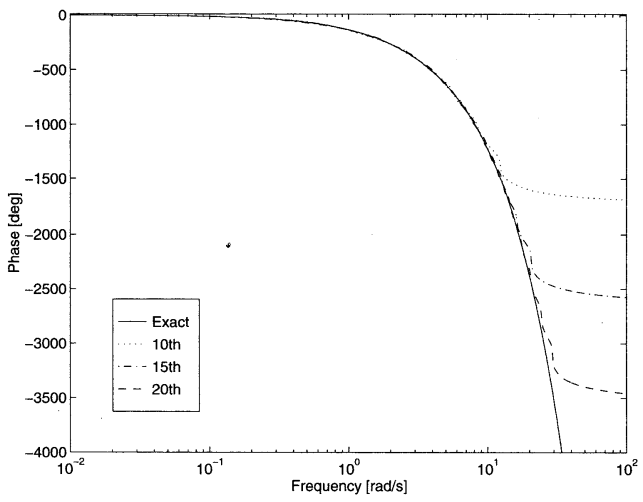

Phase

Fig. 6 Bode plots of balanced reduction (from $u_{1}$ to $y$ ) for an input time delay system

似の次数を上げると低周波数帯から誤差が少なくなるこ とが確認できる。

Figs. 8, 9 は近似系の $u_{1}-y$ と $u_{2}-y$ 間のインパルス応 答を示したものである。これらの結果から, むだ時間分 遅れて応答が発生する様子が良好に再現できていること がわかる。

(2) 一方向性むだ時間系

$$
\begin{aligned}
{\left[\begin{array}{l}
y_{1}(s) \\
y_{2}(s)
\end{array}\right]=} & {\left[\begin{array}{cc}
\frac{1}{s+1} & 0 \\
\frac{e^{-5 s}}{(s+1)^{2}} & \frac{1}{s+1}
\end{array}\right]\left[\begin{array}{l}
u_{1}(s) \\
u_{2}(s)
\end{array}\right] } \\
& \text { むだ時間 }: h_{1}=5.0 \text { 秒 }
\end{aligned}
$$

をそれぞれ $5,8,10$ 次に近似し, 得られた近似系の性質 を調べた（Figs. 10,11）。

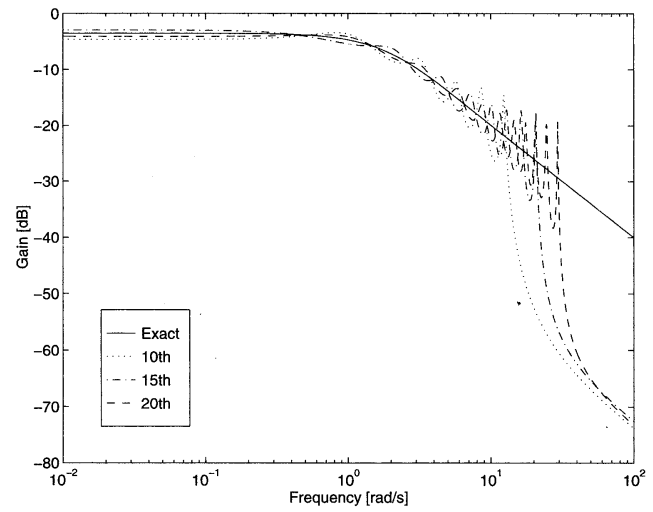

Gain

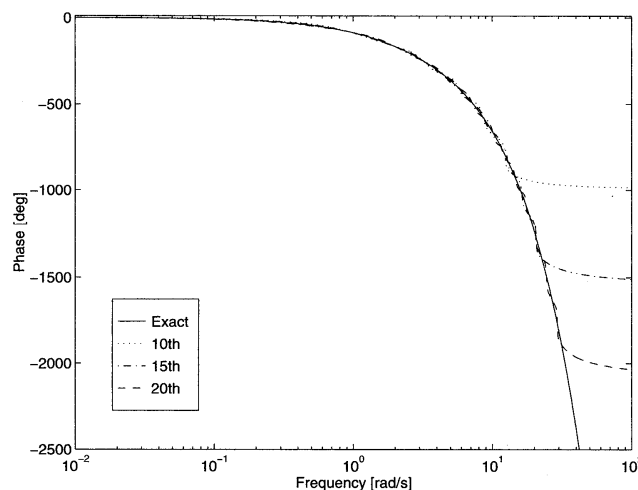

Phase

Fig. 7 Bode plots of balanced reduction (from $u_{2}$ to $y$ ) for an input time delay system

Fig. 10 は近似系の $\sigma$-plot を表したもので，すべての 周波数において良好な近似が得られている. 近似の次数 を上げると低周波数帯から誤差が少なくなり，本来の系 の応答に近付く.

Fig. 11 は近似系の $u_{1}-y_{2}$ 間のインパルス応答を示し たものである。この系は $u_{1}-y_{2}$ 間にだけむだ時間による 影響が現れる。一方向性むだ時間系においても，むだ時 間分遅れて応答が発生する様子が良好に再現できている ことがわかる.

\section{6. おわりに}

本稿では，入力むだ時間が独立したチャネルに存在す る系と, 一方向性むだ時間系のハンケル特異值・特異ベク トルの計算法を考察した. そして, ハンケル特異值が超 越方程式の根により特徵づけられ, 特異ベクトルが常微 


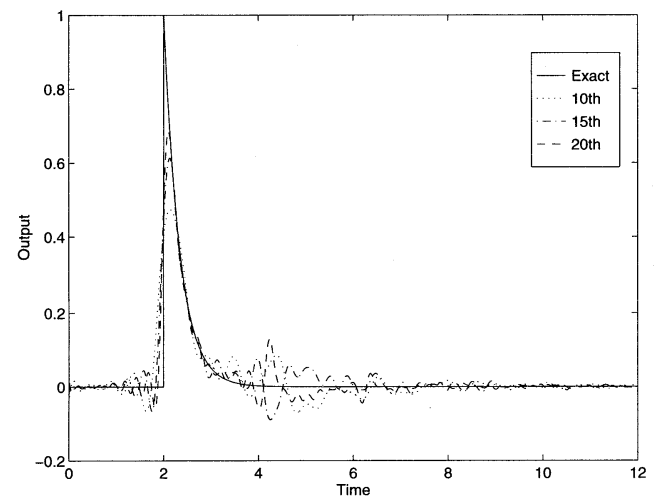

Fig. 8 Impulse responses of balanced reduction (from $u_{1}$ to $y$ ) for an input time delay system

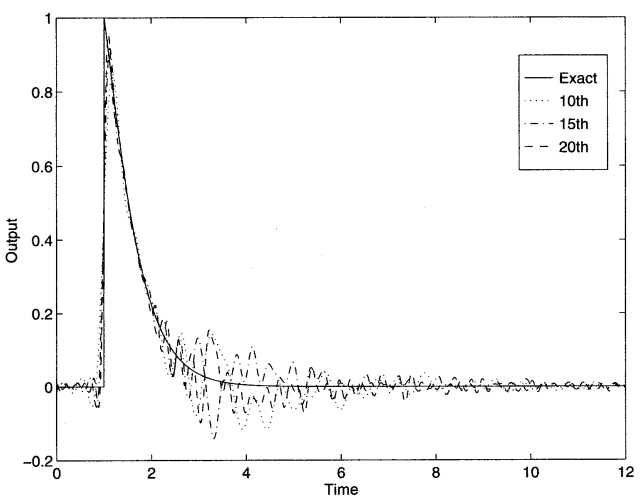

Fig. 9 Impulse responses of balanced reduction (from $u_{2}$ to $y$ ) for an input time delay system

分方程式の解により与えられることを明らかにした。ま た，数值例を用い平衡実現により得られた近似系がむた 時間系の性質を良好に保存することを示した。本稿で用 いた補助系に基づく計算法は一方向性むだ時間系に限ら ず，入力むだ時間系に置き換えることが可能な系ならば， 同様にしてハンケル特異値を導出することが可能と考え られる。

最後に，本論文の記述に関して建設的な御意見をいた だいた査読者の方々に謝意を表します。

\section{参考文献}

1) 安達, 児島, 石島: 入力にむだ時間を含む系の有限次元近似 について, 1994 年度修士論文

2) R. F. Curtain and K. Glover: Balanced realizations

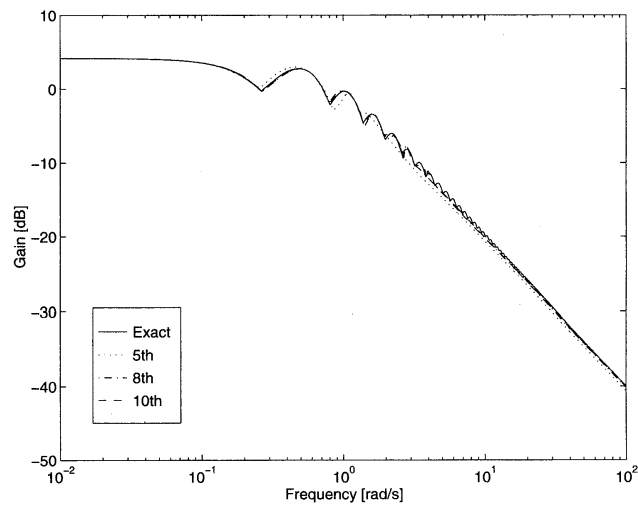

Fig. $10 \sigma$-plots of balanced reduction for a unilateral time delay system

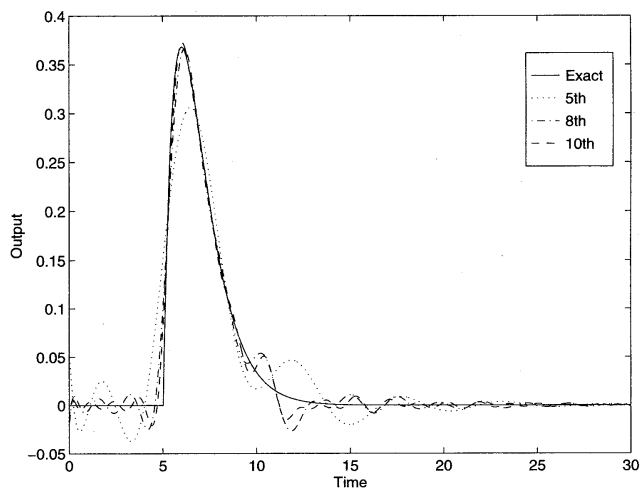

Fig. 11 Impulse responses of balanced reduction (from $u_{1}$ to $y_{2}$ ) for a unilateral time delay system

for infinite dimensional systems; Proc. Workshop on Operator Theory and Systems, H. Bart, I. Gohberg and M. A. Kaashoek, eds., Birkhäuser-Verlag, Basel, 1986, Amsterdam, the Netherlands, June 4-7 (1985)

3) D. F. Enns: Model reduction with balanced realization; 23rd $C D C$, pp. 127-132 (1984)

4) B. A. Francis: A Course in $H_{\infty}$ Control Theory, Springer-Verlag (1987)

5) 藤中, 荒木：一方向性むだ時間系に対する離散形最適レギ ユレータ問題の解法; 計測自動制御学会論文集, Vol. 20, No. 4, pp. 288-293 (1984)

6) K. Glover, J. Lam and J. R. Partington: Rational approximation of a class of infinite-dimensional systems; Report CUED/F INFENG/TR. 20, Cambridge University, U. K. (1988)

7) K. Glover, R. F. Curtain and J. R. Partington: Realisation and approximation of linear infinitedimensional systems with error bounds; SIAM J. Control and Optimization, Vol. 26, No. 4, pp. 863898 (1988) 
8) I. C. Hwang, H. Nishino and Y. Ohta: On the Hankel singular values of input time delay systems; Trans. of the Society of Instrument and Control Engineers, Vol. 31, No. 10, pp. 1650-1657 (1995)

9) 泉, 児島, 石島：一方向性むだ時間系のハンケル特異值につ いて; 第 39 回自動制御連合講演会, pp. 149-152 (1996)

10) 児島, 石島：入力むだ時間系の可制御性/可観測性グラミア ン一複数のむだ時間が存在する場合一; 第 34 回 計測自動制御 学会学術講演会予稿集, pp. 697-698 (1995)

11）児島，安達，石島：入力むだ時間系の可制御性・可観測性グ ラミアン 一有限次元近似への応用一; 計測自動制御学会論文 集, Vol. 33, No. 4, pp. 260-267 (1997)

12) 太田, 児島：入力むだ時間系のハンケル特異値一準分離型積 分核のグラミアンをもつクラスー; 計測自動制御学会論文集, Vol. 34, No. 6, pp. 523-531 (1998)

13) A. J. Prichard and D. Salamon: The linear-quadratic control problem for retarded systems with delays in control and observation; IMA J. Math. Contr. Inform. 2, pp. 335-361 (1985) 